\title{
Establishment of sustainable health science for future generations: from a hundred years ago to a hundred years in the future
}

\author{
Chisato Mori · Emiko Todaka
}

Received: 20 August 2008/Accepted: 3 September 2008/Published online: 8 October 2008

(c) The Japanese Society for Hygiene 2008

\begin{abstract}
Recently, we have investigated the relationship between environment and health from a scientific perspective and developed a new academic field, "Sustainable Health Science" that will contribute to creating a healthy environment for future generations. There are three key points in Sustainable Heath Science. The first key point is "focusing on future generations"- - society should improve the environment and prevent possible adverse health effects on future generations (Environmental Preventive Medicine). The second key point is the "precautious principle". The third key point is "transdisciplinary science", which means that not only medical science but also other scientific fields, such as architectural and engineering science, should be involved. Here, we introduce our recent challenging project "Chemiless Town Project", in which a model town is under construction with fewer chemicals. In
\end{abstract}

The content of this paper was presented in the special lecture at the 78th Japan Hygiene Meeting, 2008.

C. Mori $(\bowtie) \cdot$ E. Todaka

Department of Bioenvironmental Medicine,

Graduate School of Medicine,

Chiba University, Chiba 260-8670, Japan

e-mail: cmori@faculty.chiba-u.jp

C. Mori · E. Todaka

Center for Environment Health and Field Sciences,

Chiba University, Chiba 277-0882, Japan

C. Mori · E. Todaka

Chiba University Association for Research in Sustainability

Science (CARSS), Chiba University, Chiba 277-0882, Japan

C. Mori

Center for Preventive Medical Science,

Chiba University, Chiba 260-8670, Japan the project, a trial of an education program and a healthexamination system of chemical exposure is going to be conducted. In the future, we are aiming to establish health examination of exposure to chemicals of women of reproductive age so that the risk of adverse health effects to future generations will decrease and they can enjoy a better quality of life. We hope that society will accept the importance of forming a sustainable society for future generations not only with regard to chemicals but also to the whole surrounding environment. As the proverb of American native people tells us, we should live considering the effects on seven generations in the future.

Keywords Sustainable health science $\cdot$ Environmental preventive medicine - Future generations - Precautious principle $\cdot$ Chemiless Town Project

\section{Introduction}

In modern society, people enjoy healthy and a convenient life style with highly developed technology. On the other hand, rapid economic growth based on mass production, mass consumption, and mass disposal has caused global environmental problems and health disorders originating in the environment [1-5].

People have taken action about the global environmental problems such as global warming, global pollution, and ozone layer depletion. Therefore, scientists have established "Sustainability Science" $[6,7]$ in order to improve global environmental problems. However, sufficient action on medical problems caused by environmental factors has not yet been taken in Japan or in the world. It is extremely important to study the relationship between the environment and children's health [8-10], and to improve 
environment so that we can sustain the health of children and future generations.

Japan has experienced tragic environmental diseases such as Minamata disease [11] and Itai-Itai (ouch-ouch) disease [12] in the history in the process of economic growth. From the experience, Japan at present has strict regulations with regard to environmental pollution. However, the target of current medical science is the human population who are living the modern society. If the target is the people living currently, it cannot necessarily protect future generations' health.

Therefore, we propose establishing "Sustainable Health Science", that is a new public health focusing on future generations. To protect the future generations' health, it is necessary that multi-disciplinary scientists gather and establish transdisciplinary "Sustainable Health Science".

Here, we introduce the background, the concept, and our recent activity in "Sustainable Health Science" focusing on children's and future generations' health.

\section{The background to the establishment of "Sustainable Health Science"}

About 100 years ago, many people lost their lives because of malnutrition or infectious diseases in Japan. This period can be regarded as an "era of enlightenment of public health" in Japan. The first textbook of public health in the Japanese language was published by Mori and Koike in 1897 [13]. In those days, the mission of public health was to protect the current generation's human health and to promote it. Therefore, they took action on social infrastructure such as sewage planning and town planning, etc.

In the past 50 years, mass production, mass consumption, and mass waste as a result of rapid economic growth have caused several environmental problems and diseases related to environmental factors $[5,11]$. In order to improve global environmental problems such as global warming, global pollution, and ozone layer depletion, the study of "Sustainability Science" was started [6, 7]. Sustainability Science involves application of multiple fields of science to attain a sustainable society. The basic concept of Sustainability Science can be found in a proverb of North American native people, which is "In our every deliberation, we must consider the impact of our decisions on the next seven generations". An academic field related to Sustainability Science is one of the most important introduced in the twenty-first century and it should be rapidly developed.

On the other hand, current medical problems caused by environmental factors have not yet been studied and action enough taken. Obviously, our life-style has changed dramatically in the past 50 years and, unlike the old days, we are surrounded by uncountable artificial chemicals in daily life $[4,5,14]$. It is time for us to stop and rethink current use of chemicals and the need to sustain health by improving the environment. From past experience, Japan at present has strict regulations with regard to environmental pollution. However, the target of current medical science is the humans who are living in modern society. If the target is modern people, it cannot necessarily protect future generations' health, since fetuses are at the most susceptible period in human life stage and higher attention should be paid.

Therefore, we propose the establishment of "Sustainable Health Sciences" which is new preventive medicine or public health focusing on future generations.

\section{The concept of "Sustainable Health Science"}

One hundred years ago, the concept of public health was to protect the current generation's health. Now, we need to establish the new public health, focusing on 100 years in the future.

In modern society, people are exposed to uncountable chemicals [4, 5, 14], however, only for a handful of chemicals are we clear about their health effects on humans. Almost nothing is clear about the relationship between multiple chemical exposure and human health, especially the effect on children and fetuses [4, 8-10, 14]. Our previous studies revealed that fetuses in Japan were contaminated by multiple chemicals that are transferred through the umbilical cord from their mothers [4, 14-16]. Most of the chemicals which were detected from the umbilical cords of newborn babies did not exist until 100 years ago, and there is no scientific proof that there is no risk of those mixtures of chemicals to human health.

As a result of our studies on the health effect of environmental chemicals, we have tried to find a way to solve the problem fundamentally [4, 14-16], and have suggested reduction of the chemicals in the environment to prevent possible adverse health effects [17-22]. We call it "Environmental Preventive Medicine (EPM)". In medical science, preventive medicine is about persuading people to inform themselves about their own health situation and leading them to take action by themselves. However, the adverse health effects of environmental pollution cannot be prevented by personal effort, especially the effect on fetuses or future generations. Therefore, society should be improved.

Here, we suggest establishing a new field of science at which society should aim in the twenty-first century"Sustainable Health Science".

There are three key points in Sustainable Health Science (Fig. 1). The first key point is the concept is focusing on 
future generations, so that EPM should be applied. The second key point is the "precautious principle" [23]. When a small phenomenon is apparent, society should take action

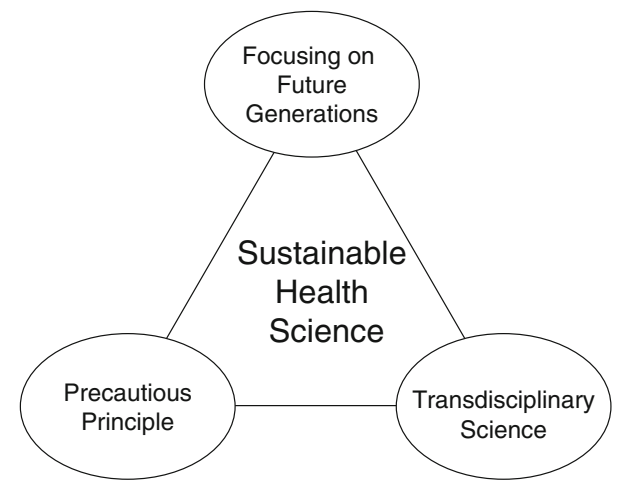

Fig. 1 There are three key points of Sustainable Health Science. The first is that it is focusing on not only the current generation but also future generations. Hence society should improve the environment so that possible adverse health effects will be prevented. It is a new public health, "Environmental Preventive Medicine". The second key point is that it is based on the precautious principle. When a small phenomenon appears, society should take action before the effect becomes obvious. The third key point is that it should be "Transdisciplinary Science". Medical science alone is not enough to protect future generation's health. Many other sciences, for example architectural and engineering sciences should be involved before the effect becomes obvious. The third key point is that it should be a transdisciplinary science [7]. To protect the future generations' health, it is necessary that multidisciplinary scientists gather and establish the Sustainable Health Sciences.

\section{Our recent activity as an example of "Sustainable Health Science" using a "Chemiless Town", an education program, and health examination}

To solve the problem of multiple chemical contamination of future generations, fundamentally we suggest building a town with only necessary amounts of chemicals. In modern society, humans enjoy healthy and long life because of the development of the chemical industry in a sense. However, on the other hand, too many unnecessary numbers and amounts of artificial chemicals might have caused modern sickness and diseases such as child allergy, bronchitis, and asthma [24].

Therefore, we are now constructing a model town with fewer chemicals on the campus of Chiba University [25]. This is a concrete example of Sustainable Health Science (Fig. 2). Also, it is urgently necessary to educate leaders

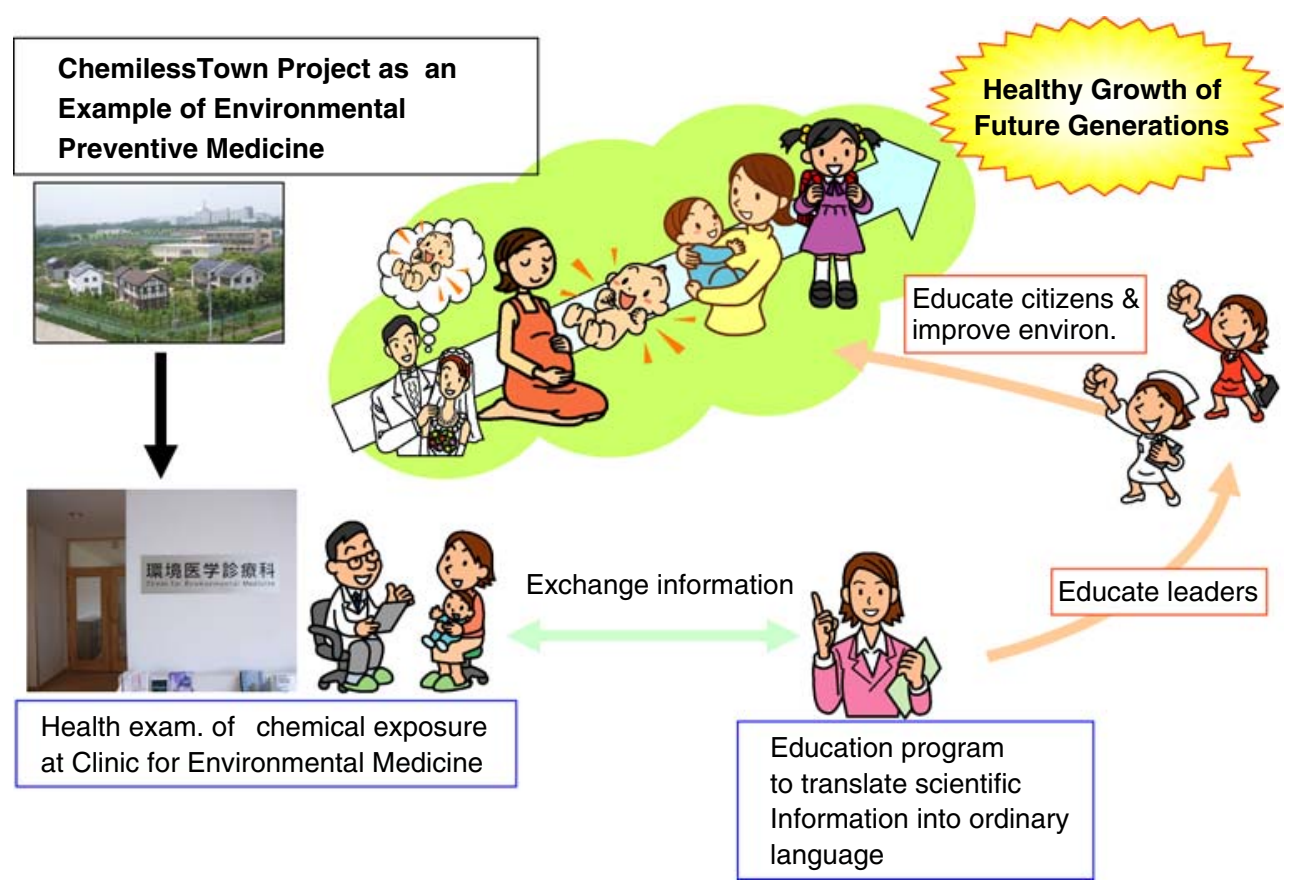

Fig. 2 Sustainable Health Science-a new field of science for future generations. Sustainable Health Science involves other scientific fields other than medical science to protect future generations' health. To improve indoor air quality, a model town with fewer chemicals (Chemiless Town) is being built and the relationship between the air quality and human health is being researched. In Chemiless Town, there is Clinic for Environmental Medicine, and people can go for a health examination to assess exposure to chemicals. If the contamination level is high at reproductive age, women receive advice and life intervention to reduce the level of contamination. Also, a trial of an education program is being conducted, to increase the number of leaders who understand the meaning of scientific research results and who can explain the problem precisely to citizens. In this way, the fruit of the Sustainable Health Science will contribute to healthy growth of future generations 
who understand the problem clearly and who can educate citizens. Therefore, we started a trial Graduate Program of sustainable health science as a Master's and Doctor's Course. Furthermore, to practice EPM, we started a healthexamination system to assess exposure to chemicals.

\section{Chemiless Town Project to prevent sick}

building syndrome

There is concern about the adverse health effects of various chemicals from building materials to humans, especially to children [26]. Since most people stay indoors, for example in private houses, schools, or office buildings, greater attention should be paid to indoor air quality. Newborn babies, especially, are in a house almost $24 \mathrm{~h}$ a day, and fetuses are influenced strongly by mothers' surrounding environment.

Currently, about $10 \%$ of the Japanese population is reported to be sensitive to, or to actually show symptoms induced by, chemicals in indoor air [27]; this is called "sick-building syndrome (SBS)" [28]. SBS is a series of symptoms, for example dizziness, headache, asthma, and throat ache, caused by volatile organic compounds (VOCs) in newly constructed or reformed buildings. It is also caused by newly purchased furniture. It is also called as "Sick-house syndrome" in Japan, and if it happens in school, it is called "Sick-school syndrome".

In Japan, indoor air quality is now regulated by national law. However, it only applies to formaldehyde and chlorpyrifos [29]. Formaldehyde must be below $0.08 \mathrm{ppm}$ and use of chlorpyrifos is, basically, prohibited. Obviously, regulation of formaldehyde alone is not enough to improve the symptoms or to prevent them.

The number of patients suffering from the syndrome is increasing, and urgent management of harmful chemicals is required. However, it is extremely difficult to find what chemicals actually cause the syndrome. It is not practical to find the cause one by one and take actions against to each chemical because the number of chemicals in indoor air is uncountable.

However, people can live healthily as long as there are no chemicals causing sickness. SBS occurs only when problematic chemicals exist in indoor air. As the first target sickness to which we can apply EPM, we chose SBS, because it seemed to be easier to approach because the problem occurs only inside buildings.

We have tried to apply EPM as a strategic method, and are now building a model town on the university campus. In the model town, houses and buildings are built with materials containing as few chemicals as possible, and it is called "Chemiless Town" [25].

In this transdisciplinary project, not only medical science, but also engineering, architectural, and agricultural

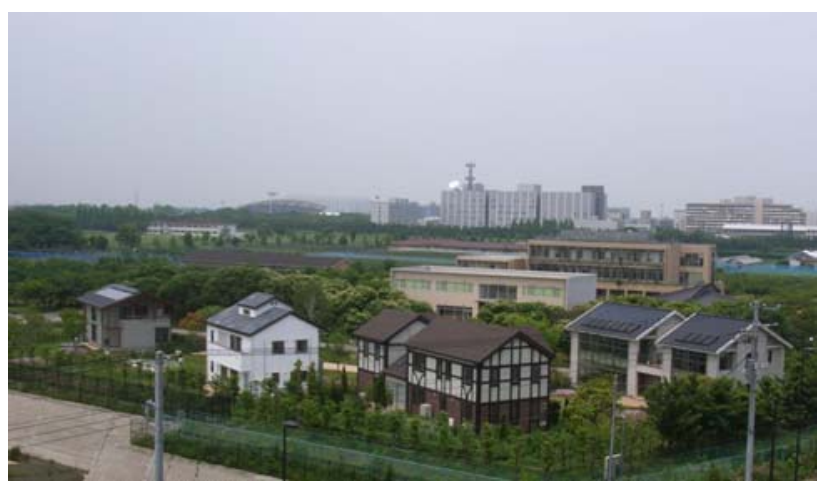

Fig. 3 A view of Chemiless Town. In Chemiless Town, there are four laboratory houses and a two-storey building in which there is a Clinic for Environmental Medicine

sciences gather for one purpose- "for the health of the future generations". In the model town, there are houses, clinic, school, and library (Fig. 3).

So far, we have analyzed and calculated the amounts of chemicals existing in the indoor air of houses and a building in Chemiless Town, and are trying to identify the sources of problematic volatile chemicals by applying a points scale. Also, at the same time, we are evaluating air quality by using healthy volunteers [30]. It has become clear that if total VOC are lower, the number of people who claim the symptoms clearly decrease.

Our goal is to build the town as a sustainable health town and people can enjoy better quality of life there. Also, we would like to spread this concept and suggest building "Chemiless Town" in many places in Japan and the world.

An attempt to introduce an educational program of Sustainable Health Science

Because sustainable health science is a quite new concept, there are almost no teachers or lecturers who can teach citizens. It is necessary to educate young people who can teach the concept in the educational field. Therefore, we started a trial graduate program as a Master's and Doctor's course. This course provides past and recent findings and knowledge about the relationship between environment and human health, and new preventive medicine and public health focusing on future generations. Students are required to be able to communicate in English and participate in group discussion.

\section{Health examination of chemical exposure}

In public health, it is quite important that people know about themselves. For example, to prevent diabetes or hypertension [31, 32], they go for health examination and they know what blood pressure they have, what is their 
heart status, they will know if their blood sugar level is high or low. Only if they know their health status, will they take action. Of course, even if they know their health status, many people do not take action and unfortunately the health status of those people usually becomes worse. Therefore, when they go through health examination, it is necessary that medical and co-medical staff intervene in the possible patient's life, and stimulate their activities such as sports, walking, food control, etc.

In the field of EPM, it is necessary that people know their own contamination level by chemicals. Currently, there is no clinic or hospital where people can receive a health examination of chemical exposure. In ChemilessTown, there is "Clinic for Environmental Medicine", and there is a system that people can receive health examination by blood sampling. In the system, PCBs are used as the representative chemicals to assess the concentration level of persistent chemicals such as organic agricultural insecticides and dioxins because many persistent organic chlorinated chemicals have a strong correlation with PCBs [33].

If the level of contamination is high, intervention in life style is practiced, such as advising him/her to avoid eating the gut of fish. If the level of contamination is very high, medication can be applied. An anion-exchange resin with an imidazolium salt on an epoxide polymer skeleton is pharmacologically useful in reducing PCBs and dioxins $[19,20,22]$.

In the future, we would like to establish a healthexamination system for women of reproductive age (Fig. 4). If the level of contamination of women of reproductive age is high, and if there is no intervention, the contaminants will be transferred to the fetuses. This may result in lower quality of life. However, if they go through a health examination for chemicals and highly contaminated women improve their life style or take medication, the risk to future babies will decrease. This will contribute to promotion of the health of future generations.

\section{Conclusion}

Rapid economic growth has caused health disorders originating in the environment. The twenty-first century is thought to be an era of preventive medicine. Recently, we have investigated the relationship between environment and health from a scientific perspective and have developed a new academic field, "Sustainable Health Science" that will contribute to the creation of a healthy environment for future generations.

In this paper, we introduced our recent challenging project the "Chemiless Town Project", in which a model

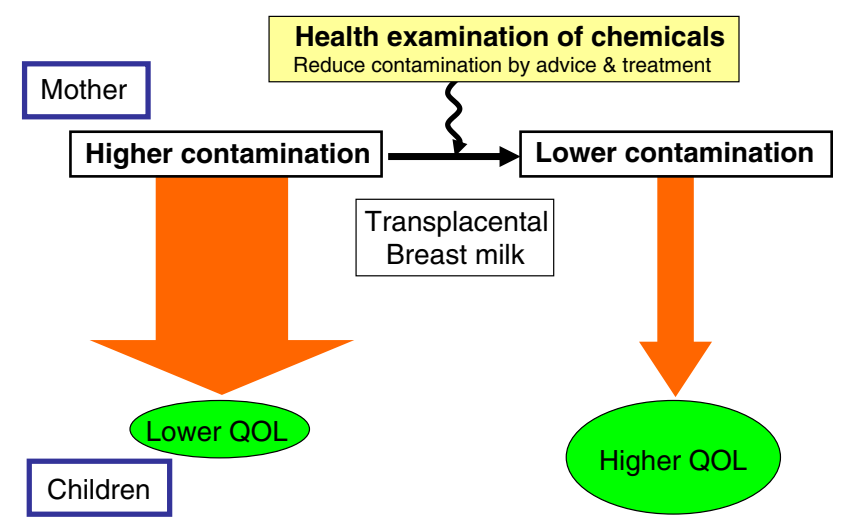

Fig. 4 Application of Environmental Preventive Medicine using a health-examination system. In the future, it is necessary to establish a health-examination system for women of reproductive age. If the level of contamination of women of reproductive age is high, and no action is taken, the contaminants will be transferred from the mother to her baby through the placenta and breast milk. This may result in higher risk for the baby, and the baby's quality of life ( $Q O L)$ may become lower. In contrast, if the women improve their life style or receive medication to reduce their contamination level, the risk to her baby may be reduced and the baby may be able to enjoy a higher QOL

town is under construction with fewer chemicals. In the project, a trial of an education program to produce leaders who can teach sustainable health science is being conducted. Furthermore, a health-examination system to assess exposure to chemicals is going to be established, because it is very important to change people by letting them know about their own contamination level. In the future, we are aiming to establish health examination to assess the exposure to chemicals of women of reproductive age so that the risk of adverse health effects to future generations will decrease and they can enjoy better quality of life.

Using the results from the project, we will spread our idea worldwide about the need for sustainable health science for future generations from the viewpoint of EPM, because multiple contamination of future generations is not confined solely to Japan.

We hope that society will recognize the importance of forming a sustainable society for future generations not only with regard to chemicals, but also the whole surrounding environment. As the proverb of American native people shows us, we should live considering the effects on seven generations in the future.

\section{References}

1. World Commission on Environment and Development (WCED). Our common future. Oxford University Press; 1987.

2. Colborn T, Dumanoski D, Myers JP. Our stolen future. New York: Dutton; 1996. 
3. McMichael AJ, Campbell-Lendrum DH, Corvalan CF, Ebi KL, Githeko A, Scheraga JD, Woodward A. Climate change and human health-risks and responses. World Health Organization, 2003.

4. Mori C. High risk group and high risk life stage: key issues in adverse effects of environmental agents on human health. Reprod Med Biol. 2004;3:51-8.

5. WHO. Preventing disease through healthy environmentstowards an estimate of the environmental burden of disease. World Health Organization. 2006. See http://www.who.int/ quantifying_ehimpacts/publications/preventingdisease/en/.

6. Clark WC, Dickson NM. Sustainability science: the emerging research program. Proc Natl Acad Sci USA. 2003;100:8059-61.

7. Komiyama H, Takeuchi K. Sustainability science: building a new discipline. Sustain Sci. 2006;1:1-6.

8. Needam LL, Sexton K. Assessing children's exposure to hazardous environmental chemicals: an overview of selected research challenges and complexities. J Exposure Anal Environ Epidemiol. 2000;10:611-29.

9. Longnecker MP, Bellinger DC, Crews D, Eskenazi B, Silbergeld EK, Woodruff TJ, et al. An approach to assessment of endocrine disruption in the National Children's Study. Environ Health Perspect. 2003;111:1691-7.

10. WHO. Children's Health and the Environment-A global perspective. World Health Organization 2005. See http://www. whqlibdoc.who.int/publications/2005/9241562927_eng.pdf.

11. Richards IS. Environmental pollutants and their fate. In: Principles and practice of toxicology in Public Health. Sudbury, Massachusetts: Jones and Bartlett Publishers; 2008. p. 79-101.

12. Nogawa K, Yamada Y, Honda R, Ishizaki M, Tsuritani I, Kawano $\mathrm{S}$, et al. The relationship between itai-itai disease among inhabitants of the Jinzu River basin and cadmium in rice. Toxicol Lett. 1983;17:263-6.

13. Mori R, Koike M. Eisei Shinpen. Nankoudo, Tokyo, 1897. (in Japanese) See http://www.kindai.ndl.go.jp/BIBibDetail.php.

14. Mori C, Komiyama M, Adachi T, Sakurai K, Nishimura D, Takashima K, et al. Application of toxicogenomic analysis to risk assessment of delayed long-term effects of multiple chemicals including endocrine disruptors in human fetuses. Environ Health Perspect. 2003;111:803-9.

15. Fukata H, Omori M, Osada H, Todaka E, Mori C. Necessity to measure $\mathrm{PCBs}$ and organochlorine pesticide concentrations in human umbilical cords for fetal exposure assessment. Environ Health Perspect. 2005;113:297-303.

16. Todaka E, Sakurai K, Fukata H, Miyagawa H, Uzuki M, Omori $\mathrm{M}$, et al. Fetal exposure to phytoestrogens-the difference of phytoestrogen status in mother and fetus. Environ Res. 2005;99:195-203.

17. Todaka E, Mori C. Necessity to establish new risk assessment and risk communication for human fetal exposure to multiple endocrine disruptors in Japan. Congenit Anom Kyoto. 2002;42:87-93.

18. Todaka E, Sakurai K, Mori C. An experimental trial to establish risk communication as a tool to decrease the risk by exposure to multiple chemicals for the future generations. Reprod Med Biol. 2005;4:65-70.
19. Sakurai K, Todaka E, Saito Y, Mori C. The pilot study to reduce dioxin in human body. Intern Med. 2004;43:792-5.

20. Sakurai K, Fukata H, Todaka E, Saito Y, Bujo H, Mori C. Colestimide reduces blood polychlorinated biphenyls (PCB) levels. Intern Med. 2006;45:327-8.

21. Toscano WA, Mori C. Molecular tools for risk assessment. In: Mark G, Toscano WA, editors. Risk assessment for environmental health". San Francisco: Jossey-Bass Inc. Pub; 2007. p. $155-72$.

22. Mochida Y, Fukata H, Matsuno Y, Mori C. Reduction of dioxins and polychlorinated biphenyls (PCBs) in human body. Fukuoka Acta Med. 2007;98:106-13.

23. Saltelli A, Funtowicz S. The precautionary principle: implications for risk management strategies. Int J Occup Med Environ Health. 2004;17:47-57.

24. Environmental Health Criteria 237. Principles for evaluating health risks in children associated with exposure to chemicals. IPCS (International programme on chemical safety), 2006. See http://www.who.int/ipcs/publications/ehc/ehc237.pdf.

25. Nakaoka H, Todaka E, Watanabe K, Mori C. Chemi-less town project to prevent sick building syndrome: from the view of the environmental preventive medicine using sustainable health town by decreasing the use of chemicals. Proceedings I of The 6th International Conference on Indoor Air Quality, Ventilation \& Energy Conservation Buildings, 2007. p. 541-7.

26. Environmental Health Criteria 59. Principles for Evaluating Health Risks from Chemicals during Infancy and Early Childhood: The Need for a Special Approach. Geneva: World Health Organization, 1986.

27. Research group on "Sensitivity difference among people and among animals" by the fund from Ministry of Health, Labour and Welfare, Government of Japan. Advice regarding the health effect by indoor air quality, 2005.

28. Housing Bureau, Ministry of Land, Infrastructure and Transport. The first report about an ideal method of building administration in order to correspond to a new problem of the 21st century, 2002 (in Japanese). See http://www.mlit.go.jp/singikai/infra/toushin/ images/01/02.pdf.

29. Housing Bureau, Ministry of Land, Infrastructure and Transport. The amended Building Standard Law on Sick House Issues. 2003. (in Japanese) See http://www.mlit.go.jp/jutakukentiku/ build/sickhouse.html.

30. Todaka E, Mori C. Attempts of environmental preventive medicine to sick building syndrome using screening test in Chemiless town. ISEE-EAC 2008 Proceeding. 194.

31. Diabetes Prevention Program Research Group. Reduction in the incidence of Type 2 Diabetes with lifestyle intervention of Metformin. N Engl J Med. 2002;346:393-403.

32. Writing Group of the PREMIER Collaborative Research Group. Effects of comprehensive lifestyle modification on blood pressure control-main results of the PREMIER Clinical Trial. JAMA. 2003;289:2083-93.

33. Mori C, Fukata H, Sakurai K, Jotaki T, Todaka E, Saito Y. Strong correlation between the concentration of dioxins and total PCBs in current Japanese people. Chemosphere. 2008;73:S235-8. 